\title{
Enhancing Cross Cultural Communication In The Marketing Classroom: A Case Approach
}

Michael C. Budden, Southeastern Louisiana University, USA

Connie B. Budden, Southeastern Louisiana University, USA

Tará Burnthorne Lopez, Southeastern Louisiana University, USA

\begin{abstract}
The importance of effective communication skills in the workplace is widely documented and recognized as a success factor in many fields of endeavor. As the workplace becomes more diverse and more global in nature, the ability to communicate across cultures is gaining in importance. A class exercise in which Panamanian educators and US students cross-interviewed each other is discussed with regard to its perceived impact on the communication process and on its ability to enlighten students on shopping behaviors of persons from another culture.
\end{abstract}

Keywords: Cross-Cultural Communication; Retailing; Shopping; Business

\section{INTRODUCTION}

$\mathrm{n}$ today's global environment, knowledge of other cultures and the ability to communicate is
imperative. Universities have been at the forefront of addressing needs in these areas. Altbach (2002)
discussed the need for American universities to develop programs and activities aimed at providing international and cross-cultural perspectives. Indeed, Shetty and Rudell (2004) felt furthering global understanding and communication was a critical element in MBA education. Juban, Baraya and Budden (2006) and Budden, Baraya and Juban (2005) discussed the advantages of study-abroad programs in developing a global perspective and avoidance of an ethnocentric outlook. Finally, Escobar, Baraya and Budden (2008) discuss the importance of enhancing the English language skills of Hispanics residing in the US.

Juban et al. (2006) proffer adult learners learn better when they are actively involved in the search for knowledge. This active involvement is prevalent in many experiential exercises. Experiential courses build upon foundation courses and require students to engage in action-oriented tasks designed to help them through their own individual learning experience (Hopkins, 1999). Thus, to improve the learning of retail management and to improve communication skills of participants, an experiential exercise was conducted involving American college students and professional educators from the Republic of Panama.

The activity, in a Retail Management class at Southeastern Louisiana University was aimed at increasing communication skills and knowledge of shopping and other habits among participants. It occurred during summer 2015. The activity included a cross-interview between Panamanian educators and US students that centered on the shopping habits of the Panamanian educators and the lives and activities of the US students. A study cited by Kuzma, Kuzma and Thiewes (2009) found surveyed firms in Britain were looking for job candidates skilled in teamwork, responsibility, extra-curricula interests and problem-solving abilities. Similarly, in a recent article by Ryan (2016), she lists 12 qualities that employers look for when hiring (2016). Four of those, thinking independently, problem solving abilities, happy to learn new things and being goal oriented reflect well on the British survey's findings. Benefits of this exercise include developing all of these traits and more.

As reported by participants, the exercise placed the participants in a new and novel situation that created tension and apprehension at the outset. Trying something new - and this was new to all participants - allows one to examine 
pre-conceived ideas and synthesize new and existing knowledge (Joyce, 1984; Rogers 2001). The present exercise required students to develop their own questions allowing them to take initiative and to be more reflective in exploring this new, cross-cultural situation.

Southeastern Louisiana University is one of four universities in the US that are involved in a program to improve the English proficiency of Panamanian educators. This multi-year program provides English as Second Language (ESL) training to Panamanian educators. While the College of Business is the coordinator of the program on the Southeastern campus, the program involves other units on campus including the College of Education, the university's Hispanic Business and Leadership Institute, and the Institute for Global and Domestic Development (a foundation tied to the university).

Each program is approximately three months long and includes development of English proficiencies among participants, training in educational processes as practiced in the US and cultural visits to enhance participants' knowledge of the US and Louisiana. Participants are encouraged to attend university sporting and cultural events while on campus. The cultural visits include trips to a university research station located in the wetlands surrounding Lake Ponchartrain, the French Quarter of New Orleans, state government offices in Baton Rouge and of course, popular shopping outlets and malls. As the first group of 50 participants was nearing the end of its program, faculty members involved in the program decided that an interactive exercise between the educators and US students could accomplish several learning goals and improve the learning experience of all involved.

Many universities identify learning outcomes at the macro level (Song, Loyle-Langholz, Higbee, \& Zhou, 2013). Such learning outcomes delineate the knowledge, skills, competencies and other products expected from students who successfully complete the effort or program involved. However, outcomes at the course level are often lacking but in this case, three specific learning outcomes for each of the two groups involved in this exercise (Panamanian educators and US retailing students) were delineated. Learning outcomes for the educators included:

1. The exercise would give the Panamanian educators an opportunity to practice and improve English communication skills (written and oral) by directly talking with and interviewing students.

2. The exercise would provide the educators a better understanding of US culture and allow them an unprecedented opportunity to closely interact with Americans.

3. The exercise would develop interviewing and cross-cultural communication skills of the educators.

The learning outcomes for the students included:

1. The exercise would give retailing students an opportunity to interact with individuals from another culture who were early in the development of their English speaking skills.

2. The exercise would give retailing students an opportunity to learn first-hand about retail shopping behaviors of persons from Central America.

3. The exercise would provide retailing students an unprecedented opportunity to practice and enhance their written and oral communication skills.

\section{The Participants}

Many Southeastern students work to support their college studies. In the College of Business more than $80 \%$ of students work full or part-time jobs. It is not unusual to hear of students with multiple part-time jobs. The university, boasting of some 15,000 students is one of the universities in the University of Louisiana System. Female students account for approximately $2 / 3$ of the student body. Twenty years ago, the College of Business had international students from almost 100 countries. Perhaps due to the downturn in the international economic climate in recent years, that number has significantly eroded, and the College now has relatively few international students creating a climate that precludes significant interaction with foreign cultures. The College has study abroad programs with trips to Costa Rica and Panama. However, only 30-60 students participate per year. Therefore, opportunities for cross-cultural experiences are somewhat limited. 
The students were juniors and seniors in a retail management class (Marketing 331) held during the summer 2015 term. The students were primarily marketing and supply chain management majors taking the class as electives in their curricula.

The Panamanian educators, primarily female and teaching in primary schools, and willing to travel to the US to participate in the 3-month long ESL program were selected by the government. The Panamanian government desires to improve the English proficiency of educators and ultimately, to improve the English abilities of the student populations impacted by these educators.

\section{The Exercise}

Panamanian educators viewed this activity as a culmination of their ESL training. They were instructed to learn as much as possible about the students each would interview (they were paired with 1-2 US students each). The crossinterview activity would last 45 minutes. At the conclusion of the exercise, educators were told they would introduce their interviewees to the class, telling not only their names, but also discussing the activities, hobbies and family situation of the students.

Retail management students in the class were encouraged beforehand to conduct a cross-interview of the Panamanians focusing on shopping habits, perceptions of shopping in the US as opposed to shopping in Panama, and to be ready to introduce their interviewees to the class with information on their shopping habits, the grades or classes they taught in Panama, and information about the background of the educators.

The students and educators were paired off at the beginning of a class. The interviews lasted approximately 45 minutes. At the conclusion, each pairing stood and took turns introducing each other to the rest of the participants. Much laughter and many smiles accompanied the introductions as all seemed to enjoy this unique experience. At the conclusion of the exercise, a short assessment questionnaire was given to each participant. The results of this assessment follow.

\section{The Results}

Students were uniformly positive about the experience. As one said, it was an eye-opening experience for students who have never left the country before. All student respondents agreed it was a positive learning experience and recommended it for future classes. A summary of each of the responses to specific questions on the assessment is displayed in Table 1.

Table 1. What did you learn from this exercise about inter-cultural communication?

1. Learning more about others' cultures can really open up to how different things are.

2. I used more slang English words that I realize. I had to adjust my style.

3. It can be difficult. Some words don't have a counterpart in other languages.

4. It taught me more about how we are just a small part of the entire world.

5. I learned we are not much different from them. We have the same problems.

6. That shopping in the US and Panama are very different. I am more appreciative now.

7. It was interesting to see how fond they were of American shopping.

8. There are many similarities in wants and needs between our cultures.

9. At times, it can be difficult to comprehend the gist of what we are trying to say.

10. We were all eager to learn from one another.

11. A word can have a completely different meaning to them.

12. I learned more about Panamanian culture and retail habits than I expected I would.

13. With a little patience and the desire, you can communicate and learn something about the others.

14. Communication is not easy at times.

Again, students said the impact on their learning was significant. They enjoyed talking with the teachers and learned much. After the assessment, many of the participants (both students and teachers) stayed and continued conversing for quite some time. 
Another part of the assessment asked the students about the knowledge gained about the shopping experiences of the teachers while in the US. Table 2 shows the responses relative to this item.

Table 2. What did you learn about the shopping experiences of visitors to the US?

1. They liked the selection and the customer service they encountered in US stores.

2. We apparently have less aggressive sales clerks than in Panama.

3. They enjoyed buying brand name merchandise at lower prices in the US.

4. They enjoyed shopping on the internet.

5. They are not used to the "quiet" shopping here - Panama's store clerks are more aggressive.

6. It is harder for them to get to stores in Hammond due to a lack of public transportation.

7. The convenience of goods is US stores is very appealing to visitors.

8 . They hate being bothered in stores by aggressive store clerks.

9. Our retailers let people shop in peace.

10. Our prices on many goods are significantly cheaper than in Panama.

11. Lack of public transport makes getting to stores difficult if you don't have a car.

12. They love getting a good deal. The outlet mall was their favorite destination here.

Finally, students were asked if they felt the communication/retail exercise should be repeated (as the program is a multi-year program)? Students were unanimous in agreeing the exercise should be continued. As one respondent put it, "it helps both parties communicate better and it was fun."

The educators also completed an assessment of the program. When asked about their ability to understand the person they interviewed, all felt they easily understood comments and responses from the students. Table 3 displays teacher responses to a question concerning what they had learned from the exercise relative to the US or our students.

Table 3. What did you learn about the US or our students from the exercise?

1. I learned about home schools. This was new to me. I had never heard of it before.

2. I learned that Americans are very clean.

3. I learned that Americans are very organized.

4. People in the streets in the US are friendly. Everyone says hello - I loved it.

5. The exercise helped our language competence.

6. We learned about your culture and your lifestyle.

7. In all places we visited, people were polite, nice and always willing to help.

8. Your students are very nice and I wish I had met them before.

9. Your students were interested in what we had to say.

10. Young people in the US want to be professional and are working hard to have a better future for them and their families.

11. I learned how the government invests in education - it is different from our country.

12. Students here have an opportunity to develop and improve their knowledge.

Panamanian educators agreed that the exercise should be continued for future program participants. Improving their listening skills was seen as a definite advantage. Just meeting and talking one on one with Americans was seen as a productive communication exercise. One even suggested the program be increased from a one-day exercise to a week-long one, where US students and Panamanian educators could work on a project and make a presentation together at the end - a change that is being discussed among those involved in the program. As one participant put it, the exercise provides a value- added benefit to both groups.

\section{SUMMARY}

To improve cross-cultural communication and an understanding of shopping behaviors of people in other countries, an exercise was conducted in a retailing class at Southeastern Louisiana University. The effort involved a crossinterview exercise where participants had to learn about each other and then introduce each other to other participants. American students and Panamanian educators agreed that it was a valuable cross-cultural exercise and 
improved the communication skills of those involved. There is an expectation that the exercise will be repeated as additional groups of educators come from Panama to participate in the ESL program.

\section{AUTHOR BIOGRAPHIES}

Michael C. Budden is a professor of Marketing and University Ombudsperson at Southeastern. His research interests include communication skills development, retail management, commercial law and ethics.

Connie B. Budden is an instructor of Management at Southeastern. Her research interests include international management, business education and organizational behavior.

Tará Burnthorne Lopez is an associate professor of Marketing at Southeastern Louisiana University. Her research interests include cross-cultural communication, marketing education and experiential exercises. In the College of Business, she is the Director of the Panama Bilingüe program.

\section{REFERENCES}

Altbach, P. G. (2002). Perspectives on internationalizing higher education. Center for Higher Education, Boston College, Boston, MA.

Budden, M.C., Baraya, A.R. \& Juban, R. L. (2005, June). Developing an MBA study-abroad program at Southeastern Louisiana University. Business Communication Quarterly, 68(2), 233-236.

Escobar, L. M., Baraya, A.R. \& Budden, M. C. Enhancing multilingual capability among Hispanics. International Business and Economics Research Journal, 7(3), 115-118.

Hopkins, R. (1999). Studying abroad as a form of experiential exercise. Liberal Education, 85(3), 36-42.

Joyce, Bruce R. (1984). Dynamic Disequilibrium: The Intelligence of Growth,” Theory into Practice, 23 (Winter), 26-34.

Juban, R. L., Baraya, A.R. \& Budden, M.C. (2006, February). Going it alone: Developing an independent study abroad program. Journal of College Teaching and Learning, 3(2), 61-66.

Kuzma, A. T., Kuzma, J. R. \& Thiewes, H. F. (2009, August). Students' expectations of a career in sales: A comparison of finance and marketing majors. American Journal of Business Education, 2(5), 45-51.

Rogers, Russell R. (1987). Educating the Reflective Practitioner: Toward a New Design for Teaching and Learning in the Professions. San Francisco: Jossey-Bass.

Ryan, L. (2016 March 2). 12 Qualities employers look for when they're hiring. Forbes.com, accessed on http://www.forbes.com/sites/lizryan/2016/03/02/12-qualities-employers-look-for-when-theyre-hiring/2/\#70c3a9501ced

Shetty, A. \& Rudell, F. (2004, November/December). Internationalizing the business program: A perspective of a small school. Journal of Education for Business, 78(20), 103-111.

Song, D., Loyle-Langholz, A., Higbee, J. L. \& Zhou, Zhou (2013, $3^{\text {rd }}$ Quarter). Achieving course objectives and student learning outcomes: Seeking student feedback on their progress. Contemporary Issues in Education Research, 6(3), $289-297$. 


\section{NOTES}

